\title{
Meta Inflacionária, Juros e Preços no Varejo Brasileiro
}

\author{
Inflation target, interests and prices Brazilian retail industry
}

\author{
FERNANDO NOGUEIRA DA COSTA*,* \\ SIMONE SILVA DE DEOS ${ }^{+,++}$ \\ JOSÉ VALNEY DE BRITO $\times$, $x \times$
}

\begin{abstract}
RESUMO: Neste artigo, analisamos as metas de inflação, com foco no mecanismo de transmissão de juros e preços. Seus fundamentos teóricos são analisados com base na literatura convencional e alternativa. Discutimos o desempenho recente do setor de varejo no Brasil, destacando como a política monetária afeta os preços, direta e indiretamente. Concluímos a avaliação crítica da meta de inflação. Nossa principal hipótese é que as taxas de juros devem ser vistas não apenas como um instrumento para controlar o nível geral de preços e o nível de atividade, regulando indiretamente a demanda agregada. Também deve ser visto como um componente fundamental e direto dos preços formados no varejo brasileiro. $\mathrm{O}$ grande risco de uma meta de inflação, por um lado, é aumentar a deflação e, por outro, criar estagflação - desemprego e inflação.

PALAVRAS-CHAVE: Regime de metas de inflação; regime cambial; canais de transmissão; comércio varejista.
\end{abstract}

ABSTRACT: In this paper we analyze inflation targeting, focusing on the interest - price transmission mechanism. Its theoretical foundations are analized based on conventional and alternative literature. We discuss the recent performance of the retail industry in Brazil, highlighting how monetary policy affects prices, both directly and indirectly. We conclude evaluating inflation targeting in a critical way. Our key hypothesis is that interest rates must

\footnotetext{
* Livre-docente do Instituto de Economia da Universidade Estadual de Campinas - IE-UNICAMP, Campinas/SP, Brasil. E-mail: fercos@eco.unicamp.br.

* Coordenador da área de Economia da Fundação de Amparo à Pesquisa do Estado de São Paulo FAPESP.

+ Doutoranda do Instituto de Economia da Universidade Estadual de Campinas - IE-UNICAMP, Campinas/SP, Brasil. E-mail: simonededeos@gmail.com.

++ Mestre em Economia pelo Instituto de Estudos e Pesquisas Econômicas da Universidade Federal do Rio Grande do Sul - IEPE/UFRGS, Porto Alegre/RS, Brasil.

$\times$ Aluno especial do Doutorado do Instituto de Economia da Universidade Estadual de Campinas IE-UNICAMP. E-mail: valney@uol.com.br.

xx Administrador de Empresas pela Fundação Getúlio Vargas - FGV/SP, São Paulo/SP, Brasil.
} 
be seen not only as an instrument to control the general price level and the level of activity, by indirectly regulating aggregate demand. It must also be seen as a fundamental and direct component of the prices formed in the Brazilian retail industry. The big risk of inflation targeting, on the one side, is to increase deflation and, on the other, to create stagflation unemployment and inflation.

KEYWORDS: Inflation target; exchange rate regime; transmission channels; retail.

JEL Classification: E31; E52; L81.

\section{INTRODUÇÃO}

Com a modificação no regime de câmbio administrado para o de câmbio flutuante, a nova diretoria do Banco Central do Brasil anunciou que passaria a adotar uma política monetária baseada em metas inflacionárias. Sucintamente, este regime consiste em subordinar a política monetária do país ao objetivo de atingir determinada taxa de inflação para um período, comunicada com antecedência. De acordo com esse sistema, o governo anuncia a inflação desejada para o futuro e o Banco Central direciona seus instrumentos, sobretudo os juros de curto prazo, para atingir suas metas, com base no diferencial entre a taxa de inflação observada e a pretendida. Mas ele não descarta o uso de instrumentos secundários, como o controle de agregados monetários (via exigência de depósitos compulsórios) e uma política discricionária de crédito.

Nosso objetivo neste artigo será analisar, de maneira teórica e aplicada, a questão do mecanismo de transmissão juros - preços no varejo, tendo como pano de fundo a discussão sobre o regime de meta inflacionária. Para isso, após esta breve introdução, faremos uma apresentação da abordagem convencional do mecanismo de transmissão da política monetária adotada pela diretoria do Banco Central do Brasil. Na terceira seção, apresentaremos a questão dos mecanismos de transmissão sob um ponto de vista alternativo, com base na Escola de Estocolmo e em Hicks. Na quarta seção, já com aplicação da teoria apresentada, faremos uma discussão do comportamento recente do varejo no Brasil, com ênfase para os efeitos microeconômicos da política macroeconômica. Mais precisamente, destacaremos como a política monetária - de juros - afeta a formação de preços no varejo: um case de mecanismo de transmissão. Na conclusão, discutiremos, criticamente, o regime de metas inflacionárias, arrolando nossas críticas a partir das evidências teóricas e aplicadas apresentadas no decorrer deste trabalho.

Nossa hipótese-chave é que a taxa de juros deve ser vista não só como instrumento de controle do nível geral de preços e do nível de atividade, via regulação indireta da demanda agregada, mas também como um componente fundamental e direto na formação dos preços praticados no varejo brasileiro. A taxa de juros é não só um item de custo efetivo, a ser repassado ao preço, mas também uma referência ao preço a ser praticado, por estabelecer o custo de oportunidade, isto é, o custo de uma segunda melhor oportunidade de lucro não aproveitada. Apresentando uma lógica financeira da formação de preços, tentaremos mostrar que o meca- 
nismo de transmissão juros - preços de varejo é praticamente imediato, ao contrário da defasagem considerada na abordagem convencional. O controle da inflação, utilizando-se somente da taxa de juros, pode ter resultados a curto prazo contraditórios ao pretendido no estabelecimento da meta inflacionária.

\section{ABORDAGEM CONVENCIONAL DO MECANISMO DE TRANSMISSÃO DA POLÍTICA MONETÁRIA}

Conforme anunciado pelas autoridades econômicas brasileiras, o inflation targeting, ora praticado, substitui a "âncora" cambial anterior. A propósito, cabe salientar que, de acordo com os critérios monetaristas de avaliação da política monetária, propostos por Friedman (1997), manter a taxa de câmbio nominal como referência básica dessa política, na ausência de coordenação de políticas macroeconômicas dos principais bancos centrais, era ter, de fato, um guia errático. Mas, segundo esses mesmos critérios, a taxa de inflação também seria um "alvo" problemático. O problema em adotar essa taxa como meta de política econômica, segundo o mencionado autor, é que a relação entre a ação da autoridade monetária e o nível de preços, embora ocorrendo, é mais indireta que a ligação entre a política praticada por esta autoridade e qualquer dos agregados monetários.

A propósito, o uso da taxa de juros nominal, de curto prazo, como instrumento principal para perseguir a meta inflacionária, também sofre reparos por parte dos monetaristas. As taxas de juros nominais seriam um mau indicador do caráter "contracionista" ou "expansionista" da política monetária, porque existiriam diferenças entre as consequências imediatas e atrasadas dessa política. A evidência empírica, segundo Friedman, revela que baixas taxas de juros (nominais) são um sinal de que a política monetária foi contracionista - a quantidade de moeda estava crescendo lentamente. Altas taxas de juros, por sua vez, são um sinal de que a política monetária foi expansionista - a quantidade de moeda estava crescendo mais rapidamente do que o nível da produção.

Desse ponto de vista, a condução da política monetária apresentaria um aparente paradoxo. O problema é que a autoridade monetária, para assegurar baixas taxas de juros nominais, deveria partir, aparentemente, em direção oposta, engajando-se numa política monetária "deflacionista", isto é, adotando uma taxa de juros ainda mais alta. As altas taxas de juros nominais (acima da taxa de inflação) no presente, refletiriam uma política "inflacionária" no passado, ou seja, com baixas taxas de juros.

O que Friedman acentua nesse raciocínio é o problema da "ilusão monetária", isto é, da defasagem de percepção, por parte dos agentes econômicos, sobre as variações de preços relativos (afetados de maneira heterogênea pela elevação da taxa de juros) e as do nível geral de preços. Mostraremos, mais adiante, na prática de formação de preços no varejo brasileiro, a dificuldade de perceber (e distinguir) as variações nominais e as reais.

É bastante difícil a tarefa de convencer a opinião pública, durante um regime 
de inflação alta, de que, mesmo com a aparência de uma taxa de juros nominal elevadíssima, a taxa não está de fato suficientemente alta em termos reais. Além disso, o uso da taxa de juros como instrumento para controle da inflação passa por outros problemas. Por exemplo, uma demora na resposta dos condutores da política de taxa de juros às mudanças na economia tende a converter os esforços discricionários estabilizadores em desestabilizantes. Tais defasagens podem constituir-se em fator desestabilizador da economia (cujas condições já teriam se alterado), quando começam a surtir efeito as ações de política econômica (Costa, 1999, cap. 9).

Vale a pena alertar para um outro aspecto da política monetária. Isso porque, ao anunciar a adoção de um novo regime de metas, o governo vem chamando a atenção para sua maior eficiência em relação a um suposto sistema anterior, que funcionaria em dois estágios: anunciava-se uma meta para os agregados monetários para, a partir dela, causar um impacto na coordenação das expectativas a respeito da inflação. O argumento é de que com a adoção do sistema de metas para a inflação vai-se diretamente ao objetivo prioritário da política econômica.

A autoridade monetária parece estar adotando, agora, a reformulação de Wicksell na Teoria Quantitativa da Moeda, percebendo o impacto maior do mecanismo de transmissão indireto sobre o nível dos preços (Costa, 1999: cap. 6). Abandona se assim, no plano retórico, o controle direto de agregados monetários - ainda que na prática esse abandono já tivesse sido feito, ou que isso tenha sido de fato pouco perseguido -, privilegiando o manejo direto dos juros.

O mecanismo de transmissão direto refere-se ao processo pelo qual a variação monetária atinge o nível de preços por meio de um efeito antecedente sobre a demanda agregada por bens e serviços, diante de uma dada oferta agregada. É interessante notar a diferença sutil em relação ao mecanismo de transmissão indireto, a la Wicksell. Neste, o incremento da oferta de crédito, devido à diminuição da taxa de juros de mercado a um patamar inferior ao da taxa de juros natural (uma taxa hipotética de equilíbrio monetário), provoca um processo cumulativo inflacionário, mas acompanhado do mecanismo direto. Portanto, mesmo alterando-se o instrumento da política monetária para a manipulação da taxa de juros, o efeito final será sempre intermediado pela variação da demanda agregada, na abordagem convencional.

Para Wicksell, assim como para a diretoria do Banco Central do Brasil, o que é válido para cada produto tomado separadamente - uma perturbação do equilíbrio entre a oferta e a procura de determinada mercadoria provocar alta ou baixa no seu preço - tem de valer, da mesma forma, para todos os produtos tomados em conjunto. Só concebendo uma alta geral dos preços por supor que toda procura (a demanda agregada sob forma monetária) está a caminho de se tornar maior que a oferta agregada de bens e serviços, em função da taxa de juros de mercado estar relativamente (à taxa natural) baixa (Costa, 2000: 121). Não há preocupação com as variações de preços relativos devido a choques. Porém, numa economia com rigidez à baixa nominal de preços e salários, essas variações implicam, necessariamente, uma elevação na média ponderada que compõe os índices de preços. Nessa 
abordagem alternativa, uma elevação do nível geral de preços não tem sempre como causa um desequilíbrio entre oferta e demanda agregadas.

No contexto do novo regime de política monetária, cujo objetivo é atingir as metas fixadas pelo governo para a inflação, o Comitê de Política Monetária do Banco Central do Brasil (COPOM) faz uma análise macroeconômica da evolução recente e das perspectivas da economia brasileira e da economia internacional. Com relação à demanda agregada, são analisados o consumo, o investimento, a execução orçamentária governamental e o hiato de recursos externos. Quanto à oferta agregada, a análise centra-se no comportamento dos indicadores de produção dos setores agropecuário e industrial e do mercado de trabalho. A respeito do cenário internacional, faz-se uma análise do desempenho das principais economias, procurando identificar as condições que possam influenciar a economia brasileira, principalmente nas suas relações com o exterior. Associados ao comportamento da economia internacional, também são analisados os movimentos de capitais, destacando-se como estes contribuíram para suprir as necessidades de pagamentos externos. A partir dessa análise macroeconômica, são traçadas as perspectivas para a evolução da inflação. Em nenhum momento discute-se os fundamentos microeconômicos dessa macroeconomia. A análise sobre o comportamento dos preços permanece no plano macroeconômico, focalizando os resultados obtidos em função das decisões de política monetária e das condições reais que independeram da ação governamental.

Entre uma alteração da taxa de juros e seu efeito na taxa de inflação e na taxa de crescimento econômico (que o COPOM também considera em seu Relatório de Inflação), há sempre uma defasagem que depende dos chamados canais de transmissão. São considerados dois canais principais, no caso brasileiro. O que passa pelos juros influencia cada componente interno da demanda agregada: consumo, investimento, gastos governamentais. Estima-se, com base na anterior regularidade histórica, que o tempo para uma mudança na taxa básica de juros repercutir, via demanda agregada, na taxa de inflação, é de seis a nove meses.

O outro canal é o que passa pela taxa de câmbio, repercutindo nos preços dos insumos importados. O efeito, calculado com base em dados do período de vigência de um regime de câmbio administrado, tem um lag ou intervalo de um a três meses. Estima-se que uma depreciação da moeda nacional de cerca de $10 \%$ eleva de $2 \%$ a 2,5\% o índice de preços ao consumidor, em um ano.

Nesse caso, deve-se considerar com atenção o regime cambial que o país passou a adotar: o regime de câmbio flutuante combina autonomia para o banco central fixar a taxa de juros com a liberdade de movimento do capital internacional. Portanto, no modelo macroeconômico adotado pelo Banco Central do Brasil ${ }^{1}$, o

\footnotetext{
${ }^{1}$ Nesse modelo, há três variáveis exógenas: a taxa de juros interna, a internacional (a estabelecida pelo banco central norte-americano) e o spread entre a taxa de um título do Tesouro norte-americano e a de um título de dívida externa brasileira. Na realidade, o Banco Central do Brasil só tem condições de manipular a primeira e a terceira.
} 
juro é exógeno, ou seja, determinado pelo banco central, e o câmbio é endógeno, isto é, determinado pelas forças do mercado cambial. Baseado numa análise dos fundamentos macroeconômicos, e não contemplando a possibilidade eventual de ser determinada por uma bolha especulativa, a taxa de câmbio é considerada como uma resultante do fluxo de bens e serviços com relação ao exterior e do fluxo de capital.

Nesse modelo macroeconômico, considera-se que a taxa de inflação e a taxa de crescimento do produto interno bruto são consequências da manipulação da taxa de juros por parte do Banco Central do Brasil, para atingir a meta inflacionária. No entanto, essa atuação não considera sua repercussão microeconômica.

Evidentemente, a possibilidade do repasse do efeito custo aos preços do varejo depende do estado da demanda agregada, com seu impacto sobre o nível da renda e do desemprego. No entanto, o esmagamento da margem de lucro, quando os custos decorrentes da elevação da taxa de câmbio ou da taxa de juros não são repassados aos preços de varejo, pode trazer sérias dificuldades às condições econômicas e financeiras das empresas do setor. $\mathrm{O}$ resultado pode ser um maior número de falências, aprofundando a recessão e o desemprego, ou sua progressiva desnacionalização.

Passaremos agora à análise de uma abordagem alternativa, focalizando mais o mecanismo de transmissão de variações na taxa de juros para a formação microeconômica de preços.

\section{ABORDAGEM ALTERNATIVA DO MECANISMO DE TRANSMISSÃO INDIRETO}

\section{Método de Desequilíbrio na Teoria dos Movimentos dos Preços}

Em sua tentativa de reformular a Teoria Quantitativa da Moeda, Wicksell teve de desfazer a relação direta entre a quantidade de moeda em circulação e o nível de preços. Como ponto de partida para explicar os movimentos do nível geral de preços, criou a abordagem através da oferta e demanda agregadas, desequilibradas via desajuste de juros. Porém, jamais deixou claro o que entendia por demanda e oferta de todos os bens.

Coube a Lindahl, economista da Escola de Estocolmo, desenvolver e sistematizar sua teoria da renda, definindo os agregados necessários à investigação do processo cumulativo. De acordo com essa interpretação, a relação entre o volume de meios de pagamentos e os preços se estabelece por intermédio do mercado de crédito. É o aumento ou diminuição da taxa de juros que, ao afetar o investimento, modifica o nível de renda e a demanda, repercutindo nos preços. A relação entre a quantidade de moeda e os preços ficou, na argumentação, reduzida a uma reação de tipo secundário - elos afastados em uma cadeia de acontecimentos -, que pode ser compensada, por exemplo, pelas variações na oferta de mercadorias, como resultado do aumento ou da diminuição do nível de produção. 
Para Lindahl (1946), o ponto de partida do investigador econômico deve residir nos planos dos agentes. Quando existem muitos sujeitos econômicos, há muitos planos distintos em ação. Partindo dos planos vigentes em determinado ponto do tempo, um economista pode explicar as ações que se apresentam com a análise microeconômica, e a totalidade do desenvolvimento (a macroeconomia) como resultado da interação dessas ações e de fatores externos, como choques aleatórios ou inesperados. Portanto, o período durante o qual todos os planos permanecem invariáveis é, forçosamente, muito curto.

Quando, nesse curto período, os preços e as quantidades vendidas são correspondentes, sob o ponto de vista não só do desejo dos compradores, senão também da vontade dos vendedores, pode-se falar de um equilíbrio de curto prazo no mercado. Em outros períodos, as expectativas dos vendedores ou dos compradores não se cumprem ao longo do processo. O desvio entre as expectativas e o curso real dos acontecimentos dá motivo a que se modifiquem os planos dos agentes. Nesse caso, pode-se falar de um desequilíbrio de curto prazo.

Sob um ponto de vista dinâmico (e mais realista), deve-se distinguir duas classes de ações, que são o fundamento do processo de formação de preços. Por um lado, as ações mediante as quais os preços (referidos a bens ou serviços específicos, numa quantia determinada ou indeterminada) são oferecidos pelos vendedores aos compradores. Por outro lado, as ações pelas quais essas ofertas são aceitas pela outra parte (com frequência numa extensão maior ou menor que a esperada pelos ofertantes). Ambas têm lugar em momentos do tempo definidos, porém as ofertas são válidas para um determinado período de tempo, ou até novo aviso. Assim, o processo de formação dos preços não é contínuo, sofre variações discretas.

Uma alteração dos preços oferecidos por vendedores, ou dos preços aceitos pelos compradores, está, ordinariamente, combinada com alguma modificação do plano geral dos negócios. O anúncio de novos preços, por exemplo, por certo vendedor, induzirá os concorrentes a modificarem seus próprios planos de ação e, eventualmente, os preços por eles mesmos oferecidos. A aceitação (pelos compradores) dos preços oferecidos (pelos vendedores) pode ser referida ao período de tempo que segue imediatamente ao anúncio do preço oferecido, ou a um período posterior. Se essas transações não estão de acordo com as previsões (dos vendedores) conduzirão, em muitos casos, a uma nova modificação dos planos baseados nas frustradas previsões anteriores. Porém, as reações ordinariamente não são bruscas.

Com a Escola de Estocolmo, facilitou-se uma análise da evolução dinâmica dos preços, mediante a adoção da distinção entre cálculos realizados ex ante e ex post, ou entre cálculos expectacionais e retrospectivos. O fator mais importante a influenciar as decisões dos vendedores a variar seus preços, de um período ao seguinte, é o desvio entre as transações previstas e as efetivadas. Portanto, para Lindahl, as forças que geram os movimentos correntes dos preços são, principalmente, o excesso ou a carência da demanda prevista pelos vendedores ao fixarem, anteriormente, seus preços. Até certo ponto, o preço é um fator determinado ao nível microeconômico, de maneira independente da oferta e da demanda agregada. 
$\mathrm{Na}$ teoria convencional, o preço de um dado produto é determinado a partir das condições vigentes de oferta e demanda desse produto. Estas são concebidas, abstratamente, como independentes dos próprios preços que determinam, isto é, como se os custos e as rendas não fossem afetados pelas modificações dos preços nos mercados, até o período seguinte. Mas, de acordo com uma abordagem alternativa, pode-se obter relações de renda e custo - nas quais estão baseadas as curvas de demanda e oferta, respectivamente - coordenadas com o preço corrente. Segundo Lindahl, essa última abordagem seria uma posição de equilíbrio temporal, caracterizado pela interdependência entre os preços e as funções de oferta e demanda, durante o período. Ao adotar como suposto básico que a quantidade de bens de consumo vendida é independente dos preços recebidos por eles, a teoria convencional assume um método de equilíbrio também convencional. Mas, na realidade, essa quantidade pode ser ajustada aos preços, ao menos parcialmente, por meio de variações no volume de estoques, característica do método do fix price, como veremos mais adiante. Numa análise mais realista do movimento dos preços correntes, é mais correto seguir o método do desequilíbrio, indicado anteriormente: aquele em que o desvio entre as expectativas e o curso real dos acontecimentos dá motivo a que se modifique os planos dos agentes.

A partir da análise do processo cumulativo, desenvolvida por Lindahl, investigaremos como as alterações da taxa de juros monetária afetam as expectativas e as decisões dos agentes econômicos, e quais os possíveis resultados macroeconômicos. As decisões empresariais quanto aos preços possuem um caráter crucial para o alcance das metas para a inflação.

A hipótese de uma sociedade atomizada implica que os agentes dificilmente possuem um conhecimento pormenorizado dos diversos comportamentos, na economia. Cada empreendedor ordena os diversos preços possíveis segundo a lucratividade esperada, ou seja, de acordo com suas expectativas sobre a compatibilidade de sua iniciativa com os futuros desejos e necessidades dos demais agentes, expressos no mercado. O banco central e o mercado bancário, ao estabelecerem o preço dos recursos necessários ao financiamento do capital de giro, cumprem a finalidade de ordenar, segundo essa lucratividade esperada, a viabilidade dos diversos preços considerados. O preço estabelecido nesse mercado monetário, a taxa de juros, enquanto custo de oportunidade, expressa uma coordenação das expectativas em relação ao estado geral dos negócios da economia. Supre, parcialmente, a deficiência informativa própria da sociedade atomizada.

\section{Método do Preço Fixo em Hicks}

Hicks apresenta Valor e Capital (1984) como uma obra de construção de pontes, não tanto entre a micro e a macroeconomia (como normalmente se considera), mas entre o sistema neoclássico estático e os modelos dinâmicos, no qual se distingue devidamente o passado e o futuro, tema que mais o interessava na época. Deve muito do que obteve aos economistas suecos. De Myrdal extraiu a ideia de equilíbrio temporal, um momentâneo equilíbrio de mercado no qual as expectativas 
dos preços se tomam como dadas; foi Lindahl quem o ensinou a unir seus equilíbrios temporais.

Mas a contribuição mais importante de Hicks (1989), na área de métodos de análise dinâmica, foi publicada originalmente em sueco, num livro editado em homenagem a Eric Lindahl, só sendo publicada em inglês em 1982. O ensaio tenta expor a relação entre o método ex-antelex-post dos suecos e o método de Keynes. A ideia dos modelos dinâmicos é uma relação entre capital e tempo, analisando processos, mais do que resultados estáticos.

Segundo Hicks, um mercado flex-price é aquele no qual o equilíbrio é estabelecido pela igualação da oferta e demanda, com a ajuda do jogo de mercado. Diferentemente, mercados fix-price são organizados e administrados. A ideia do método flex-price está no que Hicks chamou de método de equilíbrio temporário, enquanto fix-price é um método de desequilíbrio. Ao contrário do método fix-price, no flex-price não há preocupação com estoques, até porque o comportamento dos estoques é um indicador de manifestação do desequilíbrio. Contudo, o caminho para examinar o desequilíbrio é ter como referência o equilíbrio.

Com a ideia de equilíbrio temporário introduzida em Valor e Capital, Hicks tem em mente o que chama "Semana". ${ }^{2}$ Define a Semana (para distinguir do Dia de Marshall) como "aquele período de tempo durante o qual as variações de preços podem ser desprezadas. Em termos teóricos, isso significa que se supõe uma variação de preços não contínua, mas a pequenos intervalos. Na sua Semana, os mercados de fix-price não se equilibram via flutuações de preços. Os planejamentos, adotados numa Semana qualquer, não dependem somente dos preços correntes, mas também das expectativas dos planejadores quanto aos preços futuros. São expectativas de condições de mercado ou das escalas de demanda.

Hicks vê no método dinâmico de Lindahl a origem dos modelos fix-price. Nestes, as decisões de produção e fixação de preços são tomadas no início do período, com base nas expectativas. Ao longo do período, oferta e demanda se ajustam paulatinamente via estoques, com preços dados. Isto é, se há discrepâncias entre o nível de demanda esperado e o nível efetivo, os estoques se ajustam. Nesse caso, ao final do período, o nível de estoques observado poderá ser diferente do planejado ou desejado. Uma discrepância desse tipo fará com que os produtores revejam suas expectativas. O desequilíbrio de estoques é o motor, ou pelo menos uma parte do motor, que impulsiona o processo. A interação entre expectativas e eventos correntes, e a influência de discrepâncias entre os dois sobre as decisões de produzir, período a período, tornam o modelo fix-price dinâmico.

Para Hicks, os mercados não-organizados, cujos preços são formados através de comerciantes intermediários, foram historicamente dominantes - embora existissem eventuais mercados organizados. Contudo, declinou bastante no século atual, tendo sido em grande parte substituída pelo que chama de mercados com preço

\footnotetext{
${ }^{2} \mathrm{O}$ conceito de equilíbrio permanece fundamental na análise Hicksiana, particularmente na relação de ajustamento dos mercados com a passagem do tempo.
} 
fixo, nos quais os preços são determinados pelos próprios produtores (ou por alguma autoridade), e não por oferta e procura. Naturalmente, é certo que as condições de custo, e às vezes também as condições de demanda, afetam os preços que são fixados. Mas quando essas condições mudam, os preços não se alteram automaticamente. Portanto, segundo Hicks, o tipo antigo de mercado não-organizado, de preço flexível, estaria em via de extinção.

Pelo método de Hicks, as variações na demanda afetam o nível de preços dos produtos perecíveis ou não-reproduzíveis. Mas, numa economia capitalista, em que as firmas são predominantemente price-makers, os preços não se ajustam a diferenças entre oferta e demanda planejada. Os vendedores fixam seus preços e deixam que as quantidades vendidas se determinem pela demanda. Mas, embora tanto fabricantes como comerciantes sejam, em sua maior parte, fixadores de preços [price makers], ao invés de tomadores de preços [price-takers], os preços desempenham um papel de sinalização.

De acordo com essa abordagem, numa economia em que predominam mercados fix price, os preços se determinam pela preferência pela liquidez do vendedor ou, em outras palavras, por sua disposição de conservar estoques. Tal disposição, por sua vez, está sem dúvida orientada por suas expectativas quanto ao estado futuro do mercado. Portanto, o preço se determina, a cada momento, pela condição de que a demanda de estoques iguale a oferta. Porém, à medida que se leva em consideração um período de tempo apreciável, tem importância a entrada (e a saída) de caixa. Ainda que a inclinação a manter estoques (dependente da preferência pela liquidez) permaneça constante, um excesso da oferta sobre a demanda, no sentido do fluxo, aumentaria os estoques mantidos além da faixa de variação planejada, tendendo a provocar uma promoção via preços.

Nos mercados de preços flexíveis, o produtor só acumulará estoques quando crer que o preço que obterá, vendendo-os em algum período futuro, será melhor que o que poderia obter vendendo no presente, e compensará o custo de manutenção (e o risco de perda) desses estoques. Nesse sentido, é voluntária a acumulação de estoques. O sistema estará sempre em equilíbrio, pois, ainda que as demandas e ofertas de fluxos sejam desiguais, as demandas e ofertas totais (incluindo o que se agrega ou resta dos estoques) serão iguais todo o tempo. O método dos preços flexíveis é um método de equilíbrio temporal.

Ao contrário, o método dos preços fixos é um método de desequilíbrio. O acúmulo de estoques não é considerado (necessariamente) como voluntário, ainda que não se negue que uma parte possa ser voluntária. Num modelo de preços fixos, as demandas e ofertas não têm que ser iguais. Na verdade, não há nenhuma equação de demanda e oferta para determinar os preços. Isso não significa que os preços permaneçam constantes ao longo do tempo, ou de um determinado período até o seguinte; só se supõe que não mudam, necessariamente, sempre que a demanda e a oferta estejam em desequilíbrio.

Hicks (1989) chama a atenção para o fato de que, embora uma política simples de margem sobre o custo (mark-up) seja, naturalmente, a mais fácil de manejar, pode-se modificar o modelo para admitir a formação de preços de acordo com 
diversas políticas. Num sistema de preços rígidos, os preços devem ser fixados, no curto prazo, de modo a cobrir custos normais. Quando, por exemplo, os salários, os preços dos fornecedores e/ou os juros são aumentados, os preços do varejo são, normalmente, aumentados de modo correspondente.

$\mathrm{O}$ autor demonstra que, num sistema de preços rígidos, os vendedores mantêm estoques e suas atitudes são determinadas por suas expectativas (incertas) de variações de preços particulares - inclusive taxa de juros - no futuro. Sugere assim, implicitamente, que as expectativas de preços devem estar presentes nos modelos construídos a partir de Keynes.

No próximo tópico, fundamentados nessa abordagem alternativa à convencional, faremos uma análise do varejo brasileiro focada na discussão de mecanismos de transmissão juros - preços, tanto na seção que trata do desempenho recente do setor, quanto naquela que analisa a sistemática de formação de preços. $\mathrm{O}$ objetivo é tratar essa questão à luz da teoria aqui apresentada, com vistas à discussão posterior - na conclusão - da política de inflation targeting.

\section{MECANISMO DE TRANSMISSÃO DO IMPACTO DA POLÍTICA MONETÁRIA VIA JUROS: UMA ANÁLISE DA FORMAÇÃO DE PREÇOS NO VAREJO BRASILEIRO}

Os múltiplos fechamentos de empresas de varejo de todos os setores, no Brasil, têm sido atribuídos a sistemáticos erros de administração. Nossa hipótese explicativa, ao contrário, é que, ainda que haja componentes microeconômicos - má gestão -, o fenômeno é explicado considerando-se também os fatores macroeconômicos. Não seria razoável imaginar que uma epidemia de incompetência tenha assolado todo o grupo dos empresários brasileiros do comércio. Para discutir essa questão, e com vistas a ilustrar o impacto das políticas econômicas, sobretudo a política monetária, sobre as empresas de varejo, realizemos um exame sucinto do desempenho recente do setor.

Fatores de "longo prazo", consequências das mudanças econômicas e sociais no país, têm influenciado o desempenho do varejo. Entre esses fatores, o processo de urbanização e concentração populacional, o crescimento e a concentração da renda e a "massificação" do consumo. Tais acontecimentos provocaram mudanças significativas nos padrões de consumo, o florescimento de novos formatos de estabelecimentos comerciais e a inadequação de formas prévias de comercialização. Assim, cresceram os shopping centers, as lojas especializadas e em redes, os supermercados e os hipermercados. Paralelamente, desenvolveu-se o auto-serviço e ocorreu a descentralização geográfica das atividades comerciais.

O setor de varejo caracterizava-se pelo baixo investimento de capital próprio e elevado grau de alavancagem. Esse endividamento se fazia, tipicamente, via fornecedor, através da compra a prazo - e, em muitos casos, sem os necessários cuidados na administração das taxas de juros embutidas nesses financiamentos e no tempo de rotação dos estoques, como discutiremos mais adiante. Essas caracterís- 
ticas tornaram o setor permanentemente frágil do ponto de vista financeiro e extremamente sensível às variações de conjuntura. Uma peculiaridade do varejo brasileiro é enfrentar frequentes e bruscas flutuações de política econômica. Tais mudanças podem causar uma fragilidade financeira que, combinada a novos choques macroeconômicos, redunda em "quebras" de empresas do setor.

\section{Fatos estilizados: o comportamento nas decisões}

de preço do varejo frente aos "choques" de política

A edição do "Plano Collor", em março de 1990, debilitou fortemente as empresas do setor varejista. Uma peculiaridade desse plano é que, ao contrário de anteriores, não foi determinada uma "tablita". Esta seria uma necessidade lógica dos planos de estabilização, dadas as peculiaridades do regime de formação de preços que se desenvolveu num ambiente de alta inflação. A "tablita" era uma tabela de desconto que se aplicava às contas a pagar e aos preços de custo para expurgar a inflação neles embutida, quando ocorria o "congelamento" de preços.

É da prática comercial os comerciantes comprarem a prazo e praticarem preços à vista descontados os juros mercantis implícitos nos preços a prazo oferecidos pelos fornecedores. Os juros mercantis são uma variável fundamental nas decisões de preço. Trazer o custo nominal a valor presente, com uso rigoroso de cálculos financeiros ou com qualquer "regra de bolso", era o que permitia, em regime de alta inflação, a prática de preços "aparentemente abaixo do custo". Era comum, nessas circunstâncias, que o preço de venda à vista ao consumidor fosse mais baixo, nominalmente, que o preço (a prazo) de custo do vendedor. Um exemplo poderá tornar o argumento mais claro.

Imaginemos que uma empresa comprasse uma mercadoria por $\$ 200$ para pagamento em 30 dias, e que a expectativa fosse de inflação mensal de $100 \%$. Se a mercadoria fosse vendida no primeiro dia, era financeiramente racional que o preço praticado fosse, por exemplo, $\$ 50$, preservando uma margem de lucro "normal", ou tradicional. A "diferença negativa" poderia ser coberta, por exemplo, pela aplicação dos recursos (obtidos na venda), no mercado financeiro, a uma taxa de juros real positiva. Se esta fosse nula (taxa de juros nominal igual à taxa de inflação), a receita total de $\$ 300$ permitiria uma margem de lucro de $33 \%$.

$\mathrm{Na}$ eventualidade de um "congelamento" de preços e da adoção da "tablita", e supondo uma correspondência exata entre o fator de deflação da tablita e o indexador aplicado aos seus preços, a empresa se veria na seguinte situação. As “contas a pagar" (\$200) seriam reduzidas para $\$ 100$, o seu preço de custo de reposição, para futuras compras, também seria fixado em $\$ 100$, e o seu preço de venda congelado em $\$ 150$. Nessas circunstâncias, o "congelamento" seria neutro para a empresa em questão, porque sua margem de lucro $(33 \%)$ seria mantida, mesmo que os preços de compra e venda fossem alterados em termos nominais.

A inexistência da "tablita" - caso do Plano Collor - modifica drasticamente a situação. Voltando ao nosso exemplo: enquanto o preço de reposição (custo) fica “congelado" em $\$ 200$, o preço de venda ao consumidor torna-se aquele praticado 
no momento, isto é, \$150. Além disso, o valor do "contas a pagar" fica nominalmente inalterado, em $\$ 200$, que equivale a um acréscimo de 100\% em termos reais. Em outras palavras, não se confirma a "corrosão inflacionária" do custo (ou a oportunidade de ganho financeiro) esperada, quando se estabeleceu a negociação de compra. Como consequência da ruptura do sistema de crédito comercial, o varejo teve de se defrontar com uma redução apreciável das margens e um aumento significativo do endividamento real de curto prazo junto ao sistema de crédito bancário - para poder suportar essa redução de margem. Isso num contexto de forte depressão do consumo e elevadas taxas de juros, que se seguiu ao confisco de liquidez da economia.

A partir de então, as empresas do setor iniciaram um esforço de recuperação, mas muitas não resistiram. Algumas "sobreviventes" acumularam fragilidades financeiras - elevado grau de endividamento de curto prazo, a custos incompatíveis - que as comprometeriam definitivamente. Processos de reestruturação, downsizing, reengenharia, e mesmo o encerramento de empresas, foram comuns a partir de então.

A edição do Plano Real, em julho de 1994, trouxe, inicialmente, fôlego ao setor. Houve um estímulo às vendas com a queda da inflação e, devido a essa "bolha de consumo", aquecimento no nível de atividade. Além disso, a introdução da URV tornou desnecessária a discussão em torno da aplicação ou não da "tablita”, com as distorções decorrentes. No entanto, a política econômica continuou a sancionar os juros reais altos, principalmente após o agravamento do déficit do balanço de transações correntes e a necessidade crescente de atrair capitais estrangeiros para cobri-lo.

Outro ponto importante a considerar, nesse contexto, diz respeito ao comportamento do consumidor diante de uma alteração drástica do regime de inflação. Vamos, para isso, estabelecer uma tipologia do seu comportamento diante de três distintas situações: inflação alta, moderada e redução brusca do patamar inflacionário. Com inflação alta e ainda juros reais elevados, as vendas a crédito caem porque o valor de cada uma das prestações é relativamente elevado, tornando-se muito próximo do preço à vista. Além disso, essa prestação representa uma proporção muito grande do salário vigente do comprador, mesmo que venha a cair ao longo do período de endividamento, com a indexação salarial. Por exemplo, considerando o valor de um bem $\$ 1.000$ e uma taxa de juros nominal de $70 \%$ ao mês, numa compra em 12 parcelas mensais (a primeira paga em 30 dias), o valor de cada prestação seria $\$ 701,20$. A percepção de que a diferença entre o preço à vista e o valor da prestação mensal poderia ser coberta já no pagamento da segunda parcela, inibe a compra a prazo. Note-se ainda que, para um salário de, por exemplo, $\$ 1.000$, o impacto inicial seria de $70 \%$, circunstância que também tende a inibir o consumo a crédito.

Em épocas de inflação moderada, observa-se a predominância de um outro comportamento do consumidor assalariado, de acordo com a expectativa em relação a seu cash flow [fluxo de caixa]. Quando o salário tem indexação (pós-fixada) e a prestação do crediário é pré-fixada, o comprador compromete uma parcela maior do seu salário com a prestação, durante os primeiros meses. No primeiro 
aumento de salário, a situação muda. Provavelmente, a última prestação pouco pesa, fato que tende a estimular a compra a crédito. Tomando os mesmos dados do exemplo anterior, mas uma taxa de juros nominal de $30 \%$ ao mês e correção salarial a cada três meses, tem-se uma prestação de $\$ 313,45$. Para um salário de $\$ 1.000$, o comprometimento inicial da renda é de $31,3 \%$. No $4^{\circ}$ mês, com o salário corrigido para, pelo menos, $\$ 2.000$ (supondo uma inflação estabilizada em $26 \%$ ao longo de 3 meses, sendo repassada integralmente aos salários no final desse período), o comprometimento cai para 15,7\%.

Numa terceira situação, com a redução brusca da inflação - caso do Plano Real -, as prestações parecem cair repentinamente. Essa "ilusão" afeta o comportamento dos consumidores acostumados a ambientes cronicamente inflacionários. Retomando os dados do exemplo anterior, mas supondo agora uma taxa de juros no crédito ao consumidor de $10 \%$ ao mês, a prestação mensal é $\$ 146,76$. Ainda conservando a memória inflacionária, o consumidor imagina que pode elevar o comprometimento de sua renda mensal com a prestação: em vez de comprar $\$ 1.000$ a prazo resolve, por exemplo, comprar o dobro, isto é, $\$ 2.000$. Nessa circunstância, a nova prestação é de $\$ 293,53$, mantendo um comprometimento de renda $(29,35 \%)$ semelhante ao inicial anterior - isto é, o que tinha em ambiente de inflação mais elevada. Mas, como os salários deixam de ser corrigidos, essa parcela relativa não é aliviada em nenhum momento. Isso significa um maior comprometimento médio real da renda, aumentando o risco de não pagamento. Às possíveis diversas causas da inadimplência, acrescenta-se mais essa.

Levando-se em conta esse comportamento desencadeado pelo Plano Real, a partir da sua segunda fase, caracterizada pela elevação dos juros e restrição quantitativa do crédito, o quadro, para o varejo, passou a ser a perversa combinação de retração econômica e queda do consumo - decorrentes tanto do processo de mudanças estruturais nas empresas, desempregando na busca de redução de custos e maior produtividade, como de taxas de juros muito elevadas. O desemprego, resultado desse quadro recessivo, é uma causa importante de inadimplência, no varejo. Certamente não é a única, mas é a mais importante. A consequência é a elevação do grau de fragilidade que já vinha se manifestando nas empresas do setor, em função do aumento da inadimplência, redução das vendas e das margens pela maior concorrência, dificuldade de obtenção de créditos etc.

\section{O impacto da taxa de juros nos preços do varejo: um case para a análise dos mecanismos de transmissão}

Entender corretamente o processo de formação de preços no varejo requer, de um lado, analisar a relação entre preço à vista e preço a prazo, manifesta tipicamente na negociação entre varejista e fornecedor. De outro lado, cabe avaliar, no âmbito da empresa, a relação entre "rotação de estoques" e "prazo de pagamento". Nossa hipótese é que, para compreender o efeito que as modificações na taxa de juros trazem para os preços - portanto, para alcançar a meta inflacionária -, é 
fundamental que se analise o funcionamento do mecanismo de formação de preços no varejo, articulando os níveis micro e macroeconômico.

Uma ideia fundamental é que a margem operacional da empresa compreende tanto os ganhos estritamente comerciais quanto os de qualquer outra natureza (inclusive financeira), decorrentes de saldos de caixa oriundos da possibilidade da rápida "rotação de estoques", em comparação com os "prazos de pagamento" recebidos dos fornecedores. Se, no agregado, a empresa tiver um tempo de rotação de estoques mais breve que o prazo médio de pagamento, pode-se inferir que a conta de mercadorias está gerando caixa. O resultado da aplicação financeira desse caixa deve, rigorosamente, somar-se à margem bruta operacional. $\mathrm{O}$ inverso também é verdadeiro: se o tempo do giro dos estoques for superior ao prazo médio de pagamento, a empresa estará necessitando aplicar capital próprio ou de terceiros para financiar estoques. O custo desses recursos é uma dedução da margem operacional.

Também devemos chamar atenção para uma distorção que pode ocorrer no processo de formação de preços no varejo. Por tradição, hábito ou desconhecimento da matemática financeira para o cálculo dos juros embutidos, o comprador do varejo, às vezes, considera o "prazo de pagamento" como a variável mais importante na negociação com os fornecedores, e não a taxa de juros mercantil cobrada por esse prazo, que, frequentemente, não é explicitada. É comum os empresários considerarem os prazos de pagamento como "ativos da empresa" - talvez pela ilusão de ter obtido "mais tempo" para a composição de sua margem de lucro. Por isso as negociações são orientadas, muitas vezes, no sentido de ampliar ao máximo esses prazos, e não para a obtenção do menor custo a "valor presente". Ocorre também que, por tradição, o fornecedor, frequentemente, não explicite a verdadeira taxa de juros, via descontos por antecipações de pagamento. Tais comportamentos fazem com que a lógica financeira de decisões de preço nem sempre seja aplicada com o devido rigor. A aplicação do mark-up praticado sobre esse preço nominal, maior por causa do prazo, amplifica o efeito dos juros nos preços. É parte da explicação da grande dispersão de preços relativos que se observa entre os estabelecimentos comerciais.

Para entendermos melhor a dinâmica do processo de formação de preços no varejo, podemos ilustrá-lo com um exemplo estilizado. Consideremos uma taxa de "custo do dinheiro" (juro nominal e/ou custo de oportunidade) de $20 \%$ ao mês. Imaginemos que, para um determinado produto, ficou contratado, entre o varejista e seu fornecedor, um preço nominal de $\$ 100$, para pagamento em 60 dias. Poderíamos supor, a partir daí, que o preço de venda final seria formado com a adição de um mark up sobre o preço de compra de $\$ 100$. Esse mark up é definido para que a empresa, considerado o seu "mix" de vendas e eventuais "quebras" (perdas ou prejuízos), atinja uma determinada margem bruta de lucro em suas vendas. Seguindo essa rationale, e supondo que coubesse ao produto em questão uma margem de lucro de $25 \%$, isto é, que $1 / 4$ do preço fosse lucro, o preço ao consumidor seria fixado em $\$ 133,33$. Mas essa prática, provavelmente, deixaria a empresa com 
preços não aceitos pelo mercado, pois estaria acima dos preços praticados pela sua concorrência. Vejamos o porquê.

Rigorosamente, o preço de custo real de cada mercadoria é o preço nominal descontado à taxa de juros vigente, entre o dia previsto para pagamento e a data em que a análise de custos está sendo realizada. É preciso considerar o juro financeiro como o custo de oportunidade na formação do juro mercantil. Retomemos o exemplo acima, para tornar mais claro o argumento. Quando a mercadoria em questão, com custo nominal de \$100, é entregue no estabelecimento do varejista, começam a ser contados os 60 dias para o efetivo pagamento. Nessa data inicial, o preço de custo real, ou seja, o “valor presente" da mercadoria, é \$69,44, descontando-se o preço nominal a ser pago em 60 dias (\$100) à taxa de juros mensal de $20 \%$, já informada.

Se a margem de lucro pretendida fosse de $25 \%$ do preço de venda, para o “primeiro dia” de oferta daquela mercadoria na loja, o preço à vista deveria ser de \$92,58 (\$ 69,44 / 0,75), e não \$133,33. Este exemplo ajuda-nos a compreender e a desvelar o "mito" de que, em ambiente de elevadas taxas de juros e/ou de inflação, as empresas de varejo vendem “abaixo do custo". O custo nominal final será de $\$ 100,00$, mas o custo real - que é o que importa - é de $\$ 69,44$, naquele dia. ${ }^{3}$ Como já apontamos anteriormente, outro ponto importante a analisar no processo de formação de preços do varejo diz respeito à relação entre rotação de estoques e prazo de pagamento. Isso porque, a partir do momento em que foi recebida, a mercadoria pode ser vendida em uma das seguintes situações: a) imediatamente, isto é, no primeiro dia; b) em algum dia intermediário, antes do vencimento da dívida; c) após o pagamento da dívida. Retomemos o nosso exemplo.

No caso (a) de venda imediata, a empresa terá em caixa os \$92,58, uma dívida a pagar de $\$ 100$, em 60 dias, e almeja pelo menos manter a margem de lucro no valor final a ser pago. No exemplo, busca no mínimo uma margem de lucro de $25 \%$, ao final dos 60 dias. Deve ficar claro que, se nada for feito em termos de aplicação dos recursos, quando a dívida vencer restará uma margem negativa, em termos nominais, de $-\$ 7,42$ (\$92,58 - \$100).

Para realizar a margem de lucro desejada, torna-se necessário que o caixa obtido com a venda $(\$ 92,58)$ seja aplicado de forma a gerar o necessário "complemento" (mínimo) de \$40,75 (\$133,33 - \$92,58). Isto poderá ser feito de algumas formas, por exemplo: 1) negociar com o fornecedor a antecipação do pagamento com desconto; 2) negociar antecipações “compensatórias" com outros fornecedores; 3) utilizar os recursos obtidos com a venda imediata para financiar vendas a prazo, com juros, ao consumidor; 4) comprar outras mercadorias à vista; 5) investir em novos negócios, se houver confiança de que o mecanismo poderá gerar um fundo disponível permanente; ou 6) aplicar no mercado financeiro, se a "taxa de aplicação" for superior à "taxa de custo" de $20 \%$.

\footnotetext{
${ }^{3} \mathrm{O}$ argumento seria o mesmo caso o varejista comprasse à vista do fornecedor, mas financiasse suas aquisições no mercado bancário de crédito.
} 
Do ponto de vista da gestão microeconômica, é uma noção básica a de que o resultado da aplicação dos excedentes de caixa faz parte da margem operacional, não podendo ser desta dissociada. Os ganhos advindos de aplicações no mercado financeiro podem, em determinadas circunstâncias, ser insuficientes para completar a "margem de lucro desejada", pelo fato de as taxas que remuneram as aplicações serem muito inferiores à taxa de juros representativa do custo de crédito, inclusive do crédito do fornecedor.

Para a hipótese (b) - venda em qualquer dia antes da data de pagamento -, a empresa deveria estabelecer mecanismos de atualização do custo e do preço de venda. A cada dia deveria ser incorporado ao estoque remanescente o "aumento de custo", equivalente ao juro de um dia. É como se esse estoque fosse "recomprado", diariamente, por um preço mais elevado. A mercadoria estocada vai ficando mais cara a cada dia - é o chamado custo de carregamento do estoque. Aumentando-se esse custo, dever-se-ia também, teoricamente, aumentar o preço de venda, para manter a margem pretendida.

Retomemos o nosso exemplo, agora para uma mercadoria vendida no $30^{\circ}$ dia. Nesse ponto, o custo da mercadoria estará em $\$ 83,33$ (valor presente, nessa data, de $\$ 100$, descontado à taxa de $20 \%$ ) e o preço de venda deverá ser de $\$ 111,10$ $(\$ 83,33$ / 0,75), para obter a margem de lucro operacional de $25 \%(\$ 27,77$ / $\$ 111,10)$. A partir daí, tudo se passa como no exemplo da mercadoria vendida no primeiro dia.

É claro que a possibilidade de reavaliar, periodicamente, custos e preços, dependerá de vários fatores. Em primeiro lugar, de fatores que podemos denominar de mercadológicos, relacionados à insatisfação dos clientes com frequentes alterações de preços, aos preços dos concorrentes etc. Adicionalmente, existem custos operacionais para alterar os preços, que dizem respeito à manutenção dos sistemas de administração de preços e de suas alterações nas lojas - é o que a literatura econômica tem chamado de "custos de menu". Além desses, fatores que podemos chamar de legais e/ou institucionais também podem inibir modificações. Por último, devemos arrolar fatores econômico-financeiros, tais como a magnitude das taxas projetadas de juros e de inflação, as alternativas de aplicação de caixa para os prazos em questão, o fato de a demanda agregada estar em expansão ou em retração, etc. A propósito, quando a previsão for de baixas taxas de juros e de inflação, poderá ser ampliada a periodicidade de revisão de preços. A dedução lógica é que o uso do instrumento taxa de juros não poderia estar submetido a uma volatilidade abrupta, pois transmitiria, imediatamente, um choque inflacionário ou deflacionário.

A terceira situação possível (c) - a venda após o vencimento da duplicata implicará em uma nova análise financeira de alternativas. A mercadoria em estoque continua a ter o seu custo acrescido a cada dia e, em tese, o preço de venda também deveria ser reajustado, correspondentemente. Devem ser estudadas as hipóteses de: a) redução do preço para liquidar o saldo de mercadorias existentes, se for concluído que o mercado não sancionará elevações de preços equivalentes ao custo financeiro de manutenção do estoque; b) renegociação com fornecedor para devo- 
lução da mercadoria, prorrogação de prazos e redução da taxa de juros dessa extensão de prazo; c) obtenção de outra fonte de recursos para financiamento dos estoques. Nesse caso, os custos financeiros incorridos na manutenção de estoques representam deduções à margem bruta, da mesma forma que as eventuais receitas representam acréscimos.

\section{CONCLUSÃO}

A inflação de demanda diz respeito ao excesso de demanda agregada em relação à oferta agregada disponível de bens e serviços. A inflação de custos está associada ao lado da oferta, quando os custos se elevam e são repassados aos preços dos produtos, mesmo em situação de demanda estável (Costa, 2000: 120).

Pode-se argumentar, por um lado, que "a expansão do custo não é causa de inflação". Isso porque, sem um aumento do poder aquisitivo e da demanda, o aumento do custo levaria ao desemprego e à recessão, e não à inflação. Em outras palavras, sem a oferta de moeda sancionar, não há aumento contínuo de preços, devido ao risco de perda de mercado. Os defensores dessa hipótese sempre colocam a "culpa" da inflação na falta do "freio" monetário.

Por outro lado, há o argumento de que "o excesso de demanda global não é causa da inflação". Preços e salários não aumentariam por pressão do mercado, mas são "aumentados" por decisões administrativas formais e explícitas. Apontam-se, então, as "falhas do mercado", devido às instituições - sindicatos e oligopólios - que obstaculizam "o livre jogo das forças de oferta e demanda", como causadoras da inflação.

Observamos que, mesmo em recessão, as empresas oligopolistas do varejo brasileiro - situação de mercado na qual, num limitado número de produtores, cada um é bastante forte para influenciar o mercado -, geralmente, repassam os aumentos de custos tarifários, cambiais e financeiros aos seus preços, para não terem sua margem de lucro esmagada. Mesmo que aproveitando de uma mera alta sazonal das vendas, como, por exemplo, no fim de ano.

O regime de metas para a inflação requer que as decisões de política monetária sejam tomadas identificando, o mais cedo possível, quaisquer fontes de pressão sobre o nível de preços da economia, ou seja, analisando os indicadores antecedentes da taxa de inflação. Mas a autoridade monetária não pode somente se preocupar em detectar sinais de pressões futuras advindas da demanda agregada. Mesmo em contextos de menor crescimento, poderá haver alguma pressão por recomposição das margens de lucro das empresas, comprimidas pela depreciação cambial, por choque externo (por exemplo, alta do preço do petróleo), pelos ajustes tarifários, por choques de oferta agrícola etc. Ela deve se preocupar com a presença de choques não antecipados.

Segundo o Relatório da Inflação (setembro de 1999: 79), “o regime de metas para a inflação prevê uma estratégia explícita de atuação da autoridade monetária, compatível com as defasagens existentes entre os ajustes dos instrumentos de po- 
lítica monetária e seus efeitos sobre o produto e a inflação. Requer a intervenção preventiva do Banco Central de forma a direcionar a trajetória futura da inflação, buscando sistematicamente a convergência para a meta pré-estabelecida".

O COPOM traça projeções para o crescimento do produto interno bruto, que, a exemplo da projeção da inflação, são apresentados em forma de leque, visando explicitar o grau de incerteza dessas projeções. Os leques de crescimento do produto são construídos com base nas mesmas hipóteses utilizadas nos leques de inflação correspondentes.

Porém, a taxa de juros não influi somente na demanda agregada e, através dela, no crescimento do produto e da inflação. Pressiona diretamente, também, como vimos, o custo financeiro do endividamento (inclusive no crédito de fornecedores) e o custo de oportunidade na formação de preço. Em outras palavras, uma oscilação brusca da taxa de juros - por exemplo, em resposta a um choque (variação de preços relativos) - poderá, imediata e contraditoriamente, provocar ou um choque inflacionário (com predomínio do efeito custo no mecanismo de transmissão), ultrapassando largamente a meta para a inflação, ou um choque deflacionário (com predomínio do efeito demanda), não alcançando nem a faixa de tolerância e agravando a recessão.

Não há modelo econométrico de previsão (nem mesmo o do Banco Central do Brasil) que, utilizando-se de séries temporais, aponte as defasagens e os resultados possíveis, em termos de taxa de inflação, com precisão. $\mathrm{Na}$ análise dinâmica da economia, parte-se da irreversibilidade do tempo: ele só avança, nunca retrocede. Uma das consequências principais desse fenômeno é que não se pode "ir ao futuro, observá-lo e retornar ao presente”, para tomar a decisão adequada em termos da fixação da taxa de juros. Da mesma forma, o passado está ultrapassado, terminado para sempre; está dado e não se pode mudá-lo. Entretanto, o passado tem a virtude de poder ser conhecido. Mas, infelizmente, os dados do passado (assim como os próprios registros do presente) são um guia precário na elaboração de qualquer modelo para indicar o futuro da economia.

A diretoria do Banco Central do Brasil tem de ter a honestidade intelectual de reconhecer, publicamente, que não possui onipotência em matéria de alcance de meta inflacionária. Seus modelos de previsão não apontam a priori qual dos efeitos - de custos ou de demanda - vai predominar. Se ela passar uma falsa imagem, ou pior, se acreditar ser onipotente, seu inevitável fracasso político a derrubará. A política de juros sempre será muito mais arte do que ciência.

\section{BIBLIOGRAFIA}

CECCHETTI, Stephen G. (1999) "Legal Structure, Financial Structure, and the Monetary Policy Transmission Mechanism". FRBNY Economic Policy Review, 5(2), julho.

Comitê de Política Monetária (COPOM) Relatório de Inflação. Brasília, Banco Central do Brasil, setembro, 1999.

COSTA, Fernando Nogueira da (1999) Economia Monetária e Financeira: uma abordagem pluralista. São Paulo, Makron Books. 
COSTA, Fernando Nogueira da (2000) Economia em 10 Lições. São Paulo: Makron Books.

FRIEDMAN, Milton (1997) “O Papel da Política Monetária”. (original de 1968) In: CARNEIRO, Ricardo. (org.) Clássicos da Economia, $2^{a}$ ed., São Paulo, Ática.

HICKS, John. (1984) Valor e Capital. São Paulo, Abril Cultural (original de 1939).

HICKS, John. (1989) Métodos del Análises Dinâmico, Dinero, Interés y Salarios. México, Fondo de Cultura Económica (original de 1982).

LINDAHL, Eric. (1946) Estudios sobre la Teoria del Dinero y del Capital. Madrid, M. Aguilar (original em inglês de 1939).

MISHKIN, Frederic S. \& POSEN, Adam S. (1997) Inflation Targeting: lessons from four countries. FRBY Economic Policy Review, August.

ROMER, David. (1993) The new keynesian synthesis. Journal of Economic Perspectives. Vol. 7, $\mathrm{n}^{\circ} 1$, winter.

WICKSELL, Knut. (1986) Lições de Economia Política. São Paulo, Nova Cultural (original de 1911). 